\title{
Global Leadership Competencies
}

\section{Maryam Hassanzadeh}

maryam.hassanzadeh@outlook.com

\author{
Prof. Dr. Abu Daud Silong
}

abudaud.silong@gmail.com

\author{
Associate Prof. Dr. Azizan Asmuni \\ Dr. Nor Wahiza Abd Wahat \\ Department of Professional Development and Continuing Education, \\ Faculty of Educational Studies, Universiti Putra Malaysia
}

Doi:10.5901/jesr.2015.v5n2p137

\begin{abstract}
This paper explores the conceptualization of global leadership and identification of global leadership competencies. It attempts to answer what are the competencies for global leadership? Researchers indicated that global leaders require a unique set of global leadership competencies to effectively fulfil their roles. They further identified seven competencies for global leaders that include: (1) culture awareness and sensitivity, (2) global mindset or perspectives, (3) learning from experiences, (4) developing and maintaining relationships, (5) communication, (6) traits or attitudes, and (7) knowledge and skills. They also have discussed on the importance to describe and identify global leadership competencies. Many organizations do not even have a set of global leadership competencies. Most have only competencies related to domestic leaders. But with rapid globalization, there is recognition for the need of more global leaders. This research examined global leadership competencies. The study employed the qualitative methodology through the in-depth interviews. The interviews were conducted with past and present top leaders of a local research university. The data from the interviews were then transcribed verbatim, coded, analysed, interpreted and discussed accordingly. The findings in this research related to global leadership competencies includes attributes, skills and knowledge. Based on the findings recommendations will be made for improving global leadership competencies.
\end{abstract}

Keywords: Global leadership, global leadership competencies, leadership, global mind-set

\section{Introduction}

This paper examines global leadership competencies from the perspective of human resource development. Human resource development (HRD) is still in its infancy and is recognized by scholars as an emerging field of study. They noted that leadership is fast becoming one of the critical areas of studies. Organizers of international conferences on HRD across Europe have noted that for many years the streams on the leadership had consistently attracted the highest number of papers submitted to the conferences (Malloch, 2008). Interest in leadership is not just confined to HRD scholars. In general, there is great interest among scholars, researchers and practitioners work and write about leadership.

HRD as a field of study is based on three major theories - economic theory, psychological theory and the system theory (Swanson. 2001). It is defined as the integrated use of training and development (T\&D), organizational development (OD), and career development (CD) by Mc Lagan (1989). In this paper HRD is considered as the learning interventions for developing global leadership competencies. Competencies are attributes, knowledge and skills for effective global leadership.

Presently leadership competencies were identified for domestic leaders (Abu Daud Silong et al., 2008, Madinah Mohamad, 2012). Abu Daud Silong identified various competencies for public sector leadership while Madinah Mohamad identified competencies for leaders in a multicultural community. 
However these were competencies for domestic leaders. For the future we need leaders that perform at the global stage. Global leaders need new sets of competencies to perform effectively (Terrel and Rosenbusch, 2013; Tubbs and Schultz, 2006; Rhinesmith, 1996 ab; Perwitt et al. 2011; Abu Daud Silong, 2010; Caliguiri, 2006; Ket De Vries, 2005). They have to operate globally in environments which are more diverse and complex.

Past and present theories on leadership were based on traditional theories such as the traits, behavioral and situational leadership theories. Researchers initially noted that effective leadership was based on certain traits. Early researchers believed that leaders were born but later they were more inclined to think that leaders were made. Vince Lombardi, the famous and legendary American football coach said: "Contrary to the opinion of many people, leaders are not born, leaders are made, and they are made by effort and hard work" (Lussier \& Achua, 2007: 9). Researchers went on to conduct more research to search for universal traits of leaders. Unfortunately, they found nothing new and conclusive regarding traits that contribute to effective leadership.

So researchers started to focus on behaviors of effective leadership (University of lowa, University Michigan, and University of Ohio). They went on to identify various styles of leadership. Mintzberg (1973) and Yulk (1994) also studied behaviors of leaders but focused on leadership roles.

Still researches were not happy with the explanation of behaviors towards effective leadership. A group of researchers under Fiedler $(1964,1967$ \& 1974) said that styles have to be matched by situations, and then leaders can be effective. This is termed as situational leadership. Other authors such as Hersey and Blanchard $(1969,1977$ \& 1988) and House et al. (1971 \& 1974) also discussed the situational leadership theories.

More recent leadership theories were discussed by Burns $(1978,2005)$ and Bass $(1990)$ on transactional and transformational leadership. While Greenleaf (1977\& 1996) introduced the servant leadership. These were considered as more recent leadership theories grouped under integrative theories.

For the future, leadership are more focused towards performance at the global stage. Hence, the concept of global leadership was introduced (Mendenhall et al., 2001; Caligiuri, 2006; Abu Daud Silong, 2008, 2009 \& 2010). Past theories were more focused on discussion of domestic leaders. But now the discussions emphasized on global leaders who have to operate in a more complex and diverse environment. So they need new sets of competencies to function more effectively. (Terrel and Rosenbusch, 2013; Tubbs and Schultz, 2006; Rhinesmith, 1996; Perwitt et al. 2011; Abu Daud Silong, 2010; Caliguiri, 2006; Ket De Vries, 2005).

This paper then try to answer the question: what is global leadership? And what are the competencies for an effective global leadership?

\section{Review of Literature}

This section provides the key concepts and theories related to the topic of global leadership competencies. It includes topics on: (a) leadership, (b) global leadership, (c) leadership competencies, (d) global leadership competencies and (e) global mind-set.

After reviewing more than 100 years literature on leadership, there are many definitions given by various scholars and researchers on the term, leadership. Abu Daud Silong (2009) after analyzing more than 20 definitions of leadership (Table 1) concluded that it is an ability to "influence, and to influence a leader must have followers and the process of influencing occurs in a context towards some kind of goals" (Abu Daud Silong, 2009: 7). Other authors such as Kouzes and Posner (2007) mentioned that leadership is about relationship between those who want to lead and those who choose to follow.

\subsection{Global leadership}

Global leadership is a recent phenomenon. It began to appear in the literature in early 1990s. The earliest publish literature on global leadership was in 2001 (Ducker, 2012). Basically "Global leadership is relatively a new concept, a fact that is testified by the lack of an established definition, a paucity of field research and limited methodological sophistication" (Ducker, 2012:1). It is very much a debatable term and little agreement what global leaders do and what qualities they possess. As a field of study it is one in its "nascence" (Mendenhall, 2008:16)There are many definitions of global leadership, for examples:

Global leaders are individuals who effect significant positive change in organizations by building communities through the development of trust and arrangement of organizational structures and processes in context involving multiple cross-boundary stakeholders, multiple sources of external cross-boundary authority, and multiple cultures under 
conditions of temporal, geographical and culture complexity (Mendenhall 2008:17).

Table 1: Definition on Leadership

\begin{tabular}{|c|c|c|}
\hline Author & $\begin{array}{c}\text { Definitions } \\
\text { Leadership is.... }\end{array}$ & Key Ideas \\
\hline Abu Daud Silong, 2009 & $\begin{array}{l}\text { About influence and to influence a leader must have } \\
\text { followers and the process of influencing occurs in a context } \\
\text { towards some kind of goals. }\end{array}$ & $\begin{array}{l}\text { Influencing followers in a context } \\
\text { towards some kind of goals }\end{array}$ \\
\hline House et al., n.d. & $\begin{array}{l}\text { The ability of an individual to influence, motivate, and } \\
\text { enable others to contribute towards the effectiveness and } \\
\text { success of the organizations of which they are members }\end{array}$ & $\begin{array}{l}\text { Influence, motivate, effectiveness and } \\
\text { success of organization }\end{array}$ \\
\hline Maxwell, 2007 & Influence - nothing more, nothing less & Influence \\
\hline Kouzes \& Posner, 2007 & $\begin{array}{l}\text { A relationship between those who aspire to lead and those } \\
\text { who choose to follow }\end{array}$ & $\begin{array}{l}\text { Relationship between a leader and } \\
\text { followers }\end{array}$ \\
\hline Valenzuela, 2007 & $\begin{array}{l}\text { The ability of developing and communicating a vision to a } \\
\text { group of people that will make that vision true }\end{array}$ & Communicating and achieving a vision \\
\hline Northouse, 2004 & $\begin{array}{l}\text { A process whereby an individual influences a group of } \\
\text { individuals to achieve a common goal }\end{array}$ & $\begin{array}{l}\text { Influencing a group to achieve a } \\
\text { common goal }\end{array}$ \\
\hline Lussier \& Achua, 2001 & $\begin{array}{l}\text { The influencing process of leaders and followers to achieve } \\
\text { organizational objectives through changes }\end{array}$ & $\begin{array}{l}\text { Influence to achieve organizational } \\
\text { objectives }\end{array}$ \\
\hline Adler, 2001 & $\begin{array}{l}\text { People whose vision, courage, and influence set ideas, } \\
\text { people, organization and societies in motion toward the } \\
\text { betterment of their organization, their community and the } \\
\text { world }\end{array}$ & $\begin{array}{l}\text { Vision and influence toward } \\
\text { betterment of organization, community } \\
\text { and world }\end{array}$ \\
\hline Gardner, 1995 & $\begin{array}{l}\text { Individuals who significantly influence the thoughts, } \\
\text { behaviors, and/or feelings of others }\end{array}$ & Influence behaviors of others \\
\hline Zaleznik, 1992 & $\begin{array}{l}\text { A process of using power to influence the thoughts and } \\
\text { actions of other people }\end{array}$ & Influence others through use of power \\
\hline Cohen, 1990 & $\begin{array}{l}\text { The art of influencing others to their maximum performance } \\
\text { to accomplish any task, objective or project }\end{array}$ & $\begin{array}{l}\text { Influence to accomplish task and } \\
\text { objective }\end{array}$ \\
\hline Bass, 1990 & $\begin{array}{l}\text { An interaction between two or more members of a group } \\
\text { that often involves a structuring or restructuring of the } \\
\text { situation and the perceptions and expectations of the } \\
\text { members }\end{array}$ & Interaction of leader and followers \\
\hline Hersey \& Blanchard, 1988 & $\begin{array}{l}\text { A process of influencing individual or group activities in } \\
\text { efforts toward achieving organizational objectives in a given } \\
\text { situation }\end{array}$ & $\begin{array}{l}\text { Influencing others to achieve } \\
\text { organizational objectives }\end{array}$ \\
\hline Hollander, 1978 & $\begin{array}{l}\text { The process of influence between a leader and those who } \\
\text { are followers }\end{array}$ & Influencing others \\
\hline Katz \& Kahn, 1978 & $\begin{array}{l}\text { The influential increment over and above mechanical } \\
\text { compliance with the routine directives of the organization }\end{array}$ & Influencing work in organization \\
\hline Greenleaf (1977) & $\begin{array}{l}\text { The servant leader is servant first. A leader is one who goes } \\
\text { ahead to guide the way... he/she may be a mother at home, } \\
\text { any person who wields influence, or the head of a vast } \\
\text { organization }\end{array}$ & $\begin{array}{l}\text { Servant leader that serves the people } \\
\text { he/she leads; one who wields } \\
\text { influence }\end{array}$ \\
\hline Fielder, 1967 & $\begin{array}{l}\text { A process of directing or coordinating the group work } \\
\text { activities }\end{array}$ & Directing and coordinating group work \\
\hline Hemphill \& Coons, 1957 & $\begin{array}{l}\text { The behavior of an individual, directing the activities of a } \\
\text { group towards a shared goal }\end{array}$ & Directing group activities \\
\hline
\end{tabular}

Source: Abu Daud Silong, 2009

Global leadership has also been defined as leaders who are "capable of operating effectively in a global environment while being respectful of cultural diversity" (Harris, Moran, \& Moran, 2004: 25).

Another definition was introduced by Caligiuri (2006), where she defined global leaders as who are in a job with some international scope (Spreitzer, McCall, \& Mahoney, 1997) and must effectively manage through complex, 
changing, and often ambiguous global environment (Bartlett \& Choshal, 1992).

After reviewing the literature there were many definitions of global leadership found. Based on the search, various definitions from 1997 until 2014 were described and discussed by many authors. From the discussions by Mendenhall et al. (2012), global leadership can be interpreted and summarized in various ways:

1. It means diversity - multiple cross-boundary, stakeholders and multiple cultures (Mendenhall et. al., 2008): geography and culture (Conger et al., 2012): culture, gender, religion or social class (Hope, 2007): diverse groups and system (Beechler \& Javidan, 2007): cultural diversity (Harris et al., 2004), diverse countries, cultures and customers (Gregersen et.al., 1998).

2. It means complexity -manage complexity (Caligiuri, 2006).

3. It means working on the global stage - ability to work on the global stage (Caligiuri and Tarique, 2009): international job scope (Caligiuri, 2006): global responsibilities (Suutari, 2002): global position such as global executive (McCall and Hollenbeck, 2002): job with international scope (Spreitzer et al., 1997), global competition and world-class performance (Brake, 1997).

4. It means global mindset - work together towards common vision and common goal for global community (Osland \& Brid, 2005): formulate and implement strategies that enhance global reputation and produce competitive advantage (Petrick, et al., 1999): able to articulate a globally encompassing vision and to communicate that vision to people around the world (Adler, 1997).

5. It means networking - to work together to achieve individual, organizational, and societal goals (Adler, 1997)

Based on the discussion, global leadership can be defined as a leader who operates on a global stage with the global mindset in an environment that is complex and diverse with competencies that includes networking and flexibility.

\subsection{Leadership competencies}

Generally, leadership competencies refer to the ability to perform certain tasks. Usually when a leader is competent, it will result in better performance. In describing competencies for Malaysian Public Sector Manogran (2000) defined competencies as follows:

Competencies are defined as a set of behavior patterns that can contribute to effective performance in the organization. It is also defined as clusters of employee behaviors that generate superior performance. Yet another definition views competencies as underlying characteristics of a person that distinguishes outstanding performance.

Applebaunm and Paese (n.d.) described competencies as the "how" of leadership. Thus, leaders need a set of competencies to do their jobs well. They refer competencies as "specific skills and abilities that impact" their leadership effectiveness.

The Malaysian Public Service Department as mentioned by Abu Daud Silong et al. (2008) in discussing about public sector managerial competencies refer them as skills, knowledge and personal attributes for competent work performance. The competencies required in an organization include managerial and technical skills as well as individual personal competence. The report concluded that competencies have three dimensions: (1) Having the ability and attributes to perform job effectively and to fulfil certain job roles and expectations; (2) being able to perform to certain standards; (3) ability to respond to the dynamics of the actual work environment.

Creative Centre for Leadership (CCL) proposed the use of a leadership competency model. Based on the research they validated competencies according to three major areas that include "leading others", "leading the organization" and "leading yourself". Each area or cluster of competency is described by specific competencies (Berke, Kossler \& Wakefield, 2008).

Abu Daud Silong et al. (2008) identified and discussed 15 core competencies for public sector leadership in Malaysia. These include competencies such as communication, team work, problem solving, relational skills, conflict resolution, project management, public relations, interpersonal skills, professionalism, visioning process and strategic thinking, leadership, training and coaching, technical skills, research skills, and change management.

Madinah Mohamad (2012), in her research identified 12 competencies for the multiracial community in Malaysia. These were: (1) Problem solving skills, (2) living skills in a multiracial community, (3) communication and interpersonal skills, (4) decision making skills, (5) skills in bringing about change, (6) skills related to the conflict resolution, (7) team work skills, (8) social and volunteer work, (9) skills in acquiring funds and resources, (10) skills in conducting programs for the community, (11) skills in developing good values and leadership practices and (12) ICT skills.

Leaders who have the necessary competencies are more likely to be more effective. Competencies can be acquired through education, training and experience. "Leadership development is becoming an increasingly critical and 
strategic imperative for organizations in the current business environment. Recent historical events and emerging trends emphasize the need to invest in the active development of leaders" (Leskiw \& Singh, 2007).

However to be effective leadership training and development must go through a systematic process. It includes such process: (1) Performing a training needs assessment, (2) determining learning objectives, (3) designing the training program, (4) conducting the training, (5) evaluating the training program.

\subsection{Global leadership competencies}

Global leader is the person who is able to work with diversity and complexity. But yet a global leader still is a leader. Thus, there is commonalities leadership roles and competencies between global leaders and domestic leaders (Thorn, 2012 \& Hazucha et al. 2012). Leaders of all organizations will face challenges to lead on global stage. People from different backgrounds, languages, beliefs and mindset are moving around the world. Thus, developing a leader who is capable to deal with diversity is vital for all organizations. Thorn (2012) describes the challenges and opportunities for global leaders as follows:

1. Managing change, especially in technology.

2. Managing complexity

3. Managing the gap between poor and rich

4. Becoming flexible and adaptable to the new environment and culture

5. Engaging diverse people

6. Declining of nation boundaries

Diversity is the result of globalization. Those leaders who got a responsibility on global stage should have strategies to work on globalization. Bartlet and Ghosal (1992) explained about the four globalization strategies for global leadership which are multi-domestic, global, international, and transnational. Later Hazucha and Katwyk (2003) discovered the roles of global leadership and they linked those roles with Bartlet and Ghosal's four globalization strategies for global leadership. Each role required a different strategy for global leaders to be success and effectiveness.

1. Market responsiveness leader who focuses on specific market which product should fit into it. These leaders should have wide knowledge about the local environment and how the product is needed for local people. Thus, multi-domestic globalization strategy is the most appropriate strategy to market responsiveness leader.

2. Global efficiency leader who focuses on integrating people in different places. Managing risk and change with a broad knowledge makes the leader successful. Global globalization strategy is suggested for the global efficiency role.

3. Worldwide learning leader who focuses on developing best practice globally. Thus, there is a balance between local responsibility and international integration. Therefore learning in diversity, innovation and "crosspollinate" knowledge are vital. International globalization strategy is applicable to worldwide learning leader's role.

4. Corporate integration leader who focuses on balancing multiple market. Hazucha and Katwyk are pointing this role as the most complex role in globalization. Transnational globalization strategy is suggested for this leadership. And the leaders require those skills to develop talent and influencing on cross cultural environment.

Nevertheless Torn (2012) highlighted five competencies required for global leadership which are strategic vision, adaptability, fostering teamwork, creating open communication and building relationship. He believed that organization should have agile actions to develop potential talent to work on globalization.

On the other hand Tubbs and Schulz (2006) mentioned another competency set for global leaders which include understanding the big picture, attitudes, the driving force, communication, innovation and creativity, leading change and teamwork and followership.

\subsection{Global mind set}

Referring to the above discussion and other studies, global mindset is one of the important competency for global leadership. Wherever we are, our organizations have a new set of global performance standard and quality. When we talk about quality, we are referring to world-class quality. We have to look at the larger picture of working. We must move from the traditional way to global performance. When we talk about global performance and working with different people, we are talking about diversity and complexity. On global stage we are working with groups of people and 
multicultural organizations. How we can reframe our boundary or biases to work with different people? What is our position in global stage? The answer to these questions will lead us to have a world view and train new mind-set especially global mind-set.

Cohen (2010) identified global mindset as "the ability to influence individuals, groups, organizations, and systems that have different intellectual, social and psychological knowledge or intelligence from your own" (Cohen, 2010:5).

Going to the future Malaysia needs to become a developed nation and trying to achieve this objective, we need a new kind of leaders who can operate on the global stage. "This global environment has not only changed the competitive landscape of business, it has also change the way which leaders must conduct business and the competencies leaders need to be successful" (Caligiuri, 2006:219). Thus, moving from domestic leaders to global leaders means they have to acquire a new set of competencies. For example, global leadership operates in a more diverse environment. That means they need the competencies to lead in diversity "most critically, those effective in leading a cross-culture have relationship competence... they bring out the best in people, building trust through emotionally, connecting with people from different background and create mutually and enhancing relationship" (Manning, 2003:21).

Malaysia has an advantage in developing leaders who can lead in diverse cultures. Malaysian leaders are exposed to leadership situations that involve diverse groups of people. The population consists of multiracial groups such as Chinese, Malays, Indians and others. More recently there are two million foreign workers working in Malaysia. They include people from various countries such as Indonesia, Vietnam, Philippines, Myanmar, India, Bangladesh, China, African countries and Middle Eastern countries. So Malaysian leaders are very much exposed to diversity. They are used to working in intra and inter-culture and cross-culture.

Malaysian leaders also have good language skills. Most of them can speak at least two languages and some can speak three or more languages. Communication is one of the key skills for effective global leadership. Thus, they have the potential to communicate and negotiate with the majority of the world population with their ability and command various languages especially English language.

\section{Methodology}

This section discussed the selection of research site and the participants, the case study using in-depth interview, collection of data and analysis of data. This methodology was chosen because it answered the questions posed in the study. The data required in-depth understanding of the phenomenon on global leadership.

\subsection{Selection of site and participants}

This study utilizes the qualitative approach. In qualitative study it is very important to make decisions regarding where to conduct the research and who to include as participants. Universiti Putra Malaysia is chosen as the site of the study because it is one of the premier universities in the country and also it is awarded one of the five research universities (RUs) in Malaysia. And more important, the researcher receives strong support and cooperation of the various parties of UPM. Further the researcher is a student of UPM and therefore quite familiar with the university structure and organization.

The selection of the participants was based on the purposive sampling procedures. The sampling included eight past and present top leaders of the Universiti Putra Malaysia.

\subsection{In-depth interview}

This research employed qualitative methodology through the in-depth interview. These interviews were conducted with eight past and present top leaders that include the Vice-Chancellors and Deputy Vice-Chancellors. The participants were contacted for their agreements to be involved in the research. The date, time and place of interview were decided after discussions with the participants. They were conducted at the residence, hotel, and office. The interviews lasted about two hours and they were recorded with their permissions. The interviews were conducted using an interview guide that has been pilot tested by the researcher.

For this research case study was utilized to explore the phenomena of global leadership. Case study has been employed in many leadership studies using the interview, observation and document analysis techniques. Thus case study is a very appropriate qualitative design because it will elicit real experiences in the process of leading among the top leaders in UPM. It is very useful technique in exploring real life situation. Thus the researcher will be able to 
understand the participants' leadership experiences in their own contexts. Through the in-depth interviews a qualitative researcher is able to understand and interpret the unique experiences of the participants. Case study "focuses on a single unit, a single instance" (Merriam et al., 2002: 179). It can be a single entity or unite around which there are boundaries. Patton (1990: 54) emphasized that case study " become particularly useful where one need to understand some special people, particular problem, or unique situation in great depth, and where one can identify cases rich in information - rich in the sense that a great deal can be learnt from a few exemplars of the phenomenon in question".

In qualitative research, the researchers is the research instrument. For the researcher to be able to conduct this research she was exposed to the qualitative methodology. Thus she enrolled in basic and advance qualitative class conducted by the department. Also, she is involved in the Putra Leadership Development Project that used qualitative methodology through in-depth interviews. Thus she has the necessary skills to conduct qualitative research.

Being involved in case study the researcher can interact with participants and the context of the research. Thus, it is a flexible technique that allows the researcher to continuously improve and refine the process appropriate to the context in new findings as the research progresses. Case study provides the opportunity for the participants to tell their stories based on their own experiences and in this research it focuses on their leadership experiences.

\subsection{Pilot study}

In qualitative research the data collection process can be refined through the pilot study. Pilot study was used to improve the interview protocol and also to learn the research process of interviewing and to improve weaknesses before starting actual research. The researcher developed the protocol for the in-depth interview based on the review of literature and also discussion with some academicians. Based on the result of the pilot study the protocol for the in-depth interviews was developed.

Pilot study was employed to test the protocol for the in-depth interview. The researcher selected a academician, who has experience in leadership position for the pilot study. In this pilot study the researcher used the same procedure as the actual study. The main propose for pilot study is to learn how to establish rapport and to integrate with the surroundings. Based on the pilot study the researcher learned skills such as taking field notes, process of interviewing and transcribing of the responses. The researcher also learn things such as the conduct of interview, the time taken to complete the interview and the questions are not very clear to participants. Based on the pilot study the researcher made several modifications to develop the final protocol for the in-depth interview.

\subsection{Analysis of data}

Data were analyzed manually. Findings were categorized into themes and categories. Data analysis were carried out simultaneously with the data collection phase. Interviews were transcribed verbatim, including pauses, laughs, and other remarks. The analysis were started as soon as transcribing was completed. The categories and themes were linked to each other so as to build a logical chain of evidence. This linkage enables us to capture the general patterns and themes for further discussion and interpretation of the findings.

Data analyses were conducted in three phases:

1. Data reduction

2. Data presentation

3. Verification of the data collected

During the analysis process the researcher used the field notes as well as the data collected from interviews. The researcher used various categories to describe effective global leadership. The researcher read the transcriptions over and over again to observe the patterns of effective leadership that were repeated. Patton (1990) termed this technique as comparative pattern analysis.

\section{Findings and Discussion}

Based on the analysis of the data three major themes are identified that includes attribute, skill and knowledge and also various categories for each of the themes. Under the theme of attribute, four categories are identified that includes open minded, idealist, adaptable and fearless. Whereas the skill include categories such as experience, global sensitivity, team working leadership skill and global critical thinking. Finally, under the theme knowledge categories of awareness and technological information. Under the category of awareness we have two sub-categories of cultural awareness and 
problem awareness identified. Cultural awareness includes sub-categories of multicultural awareness and selfawareness (Table 2).

Table 2: Findings of the Study

\begin{tabular}{|l|l|l|}
\hline \multicolumn{1}{|c|}{ Attribute } & \multicolumn{1}{|c|}{ Skill } & \multicolumn{1}{c|}{ Knowledge } \\
\hline \multirow{4}{*}{$\begin{array}{l}\text { Personality and behaviors } \\
\text { - Open minded }\end{array}$} & Leadership skill & Awareness \\
- Idealist & - Problem awareness \\
- Adaptable & Experience & Cultural awareness \\
- Fearless & $\bullet \quad$ Lifelong learning & -Multicultural \\
& $\bullet \quad$ Work experience & -Self-awareness \\
\cline { 2 - 3 } & \multicolumn{1}{|c|}{ Global sensitivity } & \multicolumn{1}{|c}{ Technology information } \\
\cline { 2 - 3 } & Global critical thinking & \\
\cline { 2 - 3 } & Team working & \\
\hline
\end{tabular}

\subsection{Attributes}

Based on this research findings, attributes include personality and behavior. Tubbs et al. (2006) explained personality as "representing the accumulation of enduring physical and mental attributes that provide an individual with his or her identity". Family, culture, and social interaction have a strong effect on personality. Among all sub personality categories open mindset ranked the highest. A person with open mindset can appreciate differences, and can accept different ideas. An open minded person is not only a good listener but also is open to select the best idea even is not her or his idea. Adaptability is another sub-category of personality. Leaders with high adaptation can perform effectively. Accept the differences of people and the high level of adaptation to the host culture is key for leaders to be successful and effective. Fearless is the last sub-category identified by this research. Willingness of person to involve herself or himself with diversity and fearless to take risk is a vital competency for global leaders.

\subsection{Skills}

As mentioned by Caliguiri (2006), global leadership needs a new set of competencies. But a global leader still is a leader. Thus, leadership competencies are required for global leaders as well. Leadership competencies such as smart, honest, communication skills, self-confidence, fairness and empowering were identified by this research. Experience is a fundamental skill for global leader. Lifelong learning is also important. However, some researchers believe that make the global leader working experience more important than lifelong learning. Undergraduate and postgraduate studying overseas, practice attending international conferences, global assignments make a skillful global leader. Another competency is international sensitivity. People with different backgrounds, ideas, beliefs, values, languages, religions have different sensitivity.

\subsection{Knowledge}

Aspiring global leaders need knowledge about host countries' culture. Among all competencies under knowledge theme, cultural awareness ranked higher. According to Earley and Ang (2003), cultural quotient (CQ) is peoples' ability to accept new cultures and can adapt themselves successfully to it. There is a vital need for organizations to enhance their talents knowledge. The knowledge they need is not only about others culture, but also about their expatriates' leaders' culture as well. Leading in uncertainty environment requires leaders' awareness about globalization challenges and problems.

\section{Conclusion}

Global leader is still a leader and needs leadership competencies such as empowering, honesty, ability to communicate, and leadership behaviors. Also global leader needs a unique set of competencies which is important to lead in diverse environments. The leader willingness and ability, skills such as making linkage, experiences to deal with different people and the ability to be successfully adaptable to new cultural settings with cultural knowledge and problem awareness.

Based on the review, findings and discussions the paper concludes that:

1. Global leadership can be defined as a leader who operates on a global stage with the global mindset in an 
environment that is complex and diverse with global competencies that include attributes, skills and knowledge.

2. Global leaders need competencies related to attributes, knowledge and skills. The attributes, knowledge and skills is shown and discussed according to Table 2.

Based on the discussion, the paper recommends that programs are provided to develop effective global leadership.

\section{References}

Abu Daud Silong, Ismi Arif Ismail, Zaharah Hassan and Soaib Asmiran. (2010). Global leadership for World Class University. Research Report submitted to the Ministry of Higher Education. Serdang: Universiti Putra Malaysia.

Abu, Daud Silong. (2009). Leadership theories, research and practices: Framing future leadership thinking. Inaugural Lecture Series, Serdang: Universiti Putra Publisher.

Abu Daud Silong, Madinah Mohamad, Zaharah Hassan \& Ismi Ariff. (2008). Changing roles and competencies for effective public sector leadership. Jurnal Pengurusan Awam, 7(1): 27-46

Abu Daud Silong. (2005). Series Preface. In Muhammad Kabilan, Zaharah Hassan, Abu Daud Silong (Editor). Readings on ethic relations in multicultural society.

Adler, N. J. (1997). Global leadership: Women leaders. Management International Review. 37(1): 171-196.Appelbaum, L., \& Paese, M. What senior leaders do: The nine roles of strategic leadership. 2008. Retrieved from h11p://www.ddilvor $1 \mathrm{~d} . c 0 m$

Bartlett. C. A., \& Choshal, S. (1992). What is a global manager? Harvard Business Review, 70(5): 124-132.

Bass, B. M. (1990). Bass \& Stogdill's Handbook of leadership: Theory, research and managerial application (3rd Ed.). New York: The Free Press.

Berke, D, Kossler, M. E., \& Wakefield, M. (2008). Developing leadership talent. San Francisco, CA: Pfeiffer.

Beechler, S., \& Javidan, M. (2007). Leading with a global mindset. In Javidan, M „. Steers, R.. \& Hitt, M. (Eds.), Advances in international management (Vol. 19, pp. 131-169). Oxford, UK: Elsevier.

Brake, T. (1997). The global leader: Critical factors for creating the world class organization. Chicago: Irwin.

Burns J. M. (1978). Leadership. New York: Harper \& Row.

Burns, J. M. (2005). Leadership. Leadership, 1(1): 11-12.

Caligiuri, P. (2006). Developing global leaders. Human Resource Management Review, 16: 219-228.

Caligiuri. P., \& Tarique. I. (2009). Predicting effectiveness in global leadership activiJournal of World Business, 44: 336-346.

Cohen, Stephen L, (2010). Effective global leadership requires a global mind-set. Industrial and Commercial Training, 42 (1), 2020: 510).

Ducker, C. (2012). Global leadership - grasping a slippery term. Encounters Mission Journal, 39: 1-9.

Earley, P.C. and Ang, S. (2003), Cultural intelligence: Individual Interactions Across Cultures, Stanford University Press, Standford, CA.

Evans, M. G. (1970). The effects of supervisory behaviors on the path-goal relationship. Organizational Behavior and Human Performance, 5: 277-298.

Fiedler, F.E. (1967). A theory of leadership effectiveness. New York: McGraw-Hill.

Fiedler, F.E. (1964). A contingency model of leadership effectiveness. In L. Berkowitz (Ed.), Advances in experimental psychology, 1:149-190, New York: Academic Press.

Fiedler, F.E. and M. M. Chemers. 1974. Leadership and effective management. Glenview, IL: Scott, Foresman.

Greenleaf, R. K. (1996). On becoming a servant leader. San Francisco: Jossey-Bass

Greenleaf, R. K. (1977). Servant leadership: A journey into the nature of legitimate power and greatness. New York: Paulist Press.

Gregersen. H. B, Morrison, A. J., \& Black, J. S. (1998). Developing leaders for the global frontier. Sloan Management Review, 40(1): 2132.

Harris, P. R., Moran, R. T., \& Moran, S. V. (2004). Managing cultural differences - global leadership strategies for the 21st century (6 th Ed). Oxford: Butterworth-Heinemann/Elsevier.

Hazucha, J., Sloan, E., \& Storfer, P. (2012). Can enterprise competency models reflect global leadership?. Industrial and Organizational Psychology, 5: 219-223.

Hersey, P., and Blanchard, K.H. (1988). Management of organizational behavior. Englewood Cliffs, NJ: Prentice Hall.

Hersey, P., and Blanchard, K. H. (1977). Management of organizational behavior: Utilizing human resources. Englewood, Cliffs, NJ: Prentice Hall.

Hersey, P., and Blanchard, K. H. (1969). Life cycle theory of leadership: Is there a best style of leadership? Training and Development Journal, 33(6):26-34.

House, R.J., and Filley, A.C. (1971). Leadership style, hierarchical influence, and the satisfaction of subordinate role expectation. A test Likert's influence proposition. Journal of applied psychology, 55: 422-432.

House, R.J, \& Dessler, G. (1974). The path-goal theory of leadership: Some post-hoc and priori tests. In J.G. Hunt and L.L. Larson (Eds.), Contingency approaches to leadership. Carbondale, IL: Southern Illinois Press.

House, R.J, \& Mitchell, T.R. (1974). Path-goal theory of leadership. Contemporary Business, 3 (Fall), 81-98.

Ket de Varies, M. F. (2005). Global executive leadership inventory. San Francisco: John Wiley and Sons. 
Kouzes, J. and Posner, B. (2007). The leadership challenge (4th $E d$.$) . San Francisco: Jossey-Bass.$

Leskiw, S. L., \& Singh, P. (2007). Leadership development: Learning from bestPractices. Leadership \& Organization Development Journal, 28(5), 444-464. doi: 10.1108/01437730710761742

Lussier, R. N., \& Achua, C. F. (2007). Effective leadership (3rd ed.). Canada: Thomson South-Western.

Northouse, P. G. (2004). Leadership theory and practice (3rd Ed.). Thousand Oaks, CV: Stage Publications.

Northouse, P. G. (1997). Leadership theory and practice. Thousand Oaks, CA: Sage Publications

Madinah Mohamad. (2012). Effective leadership among committee members in a neighborhood associations in a Malaysian multicultural community.

Madinah Mohamad., Abu Daud Silong., Azimi Hamzah, and Zaharah Hassan. (2008). Effective leadership among Committee Members of Neighborhood Associations in Malaysian community. European Journal of Social Sciences, 7(1): 147-159.

Malloch, Hedley. (2008). Conference overview. The Ninth International Conference on HRD Research and Practice across Europe, 21 23 May 2008, Lille, France.

Manning, G., \& Curtis, K. (2003). The Art of Leadership. Boston, MA: Irwin McGraw- Hill.

Manogran, P. (2000). Core competencies and the knowledge economy. Pentadbir, 5-81.

McLagan, P. a (1989). The models. A volume in Models for HRD Practices. Alexanderia, VA: American Society for Training and Development.

McCall, M. W.Jr, \& Hollenbeck, G. P. (2002). Developing global executives: The lessons of international experience. Boston, MA: Harvard Business School Press.

Mendenhall, M. E., Reiche, B. S., Brid, A., \& Osland, J. S., (2012). Defining the global in global leadership. Journal of World Business, 47(2012), 493-503.

Mendenhall. M. E , Osland. J. S., Bird, A.. Oddou, G. R., \& Maznevski, M. L (2008). Global leadership: Research, practice, and development. London and New York: Routledge.

Mendenhall, M. E., Kühlmann, T. M., \& Stahl, G. K. (2001). Developing global business leaders: Policies, processes, and innovations. London Greenwood Publishing Group

Morrison, A. J. (2000). Developing a global leadership model. Human Resource Management, 39(2-3): 117-131.

Merriam, S. B., \& Associates. (2002). Qualitative research in practice. San Francisco, CA: Jossey-Bass.

Mintzberg, H. (1973). The nature of managerial work. New York: Harper and Row.

Osland, J. S., \& Bird, A. (2005). Global leaders as experts. In Mobley, W. H., \& Weldon, E. (Eds.), Advances in global leadership (Vol. 4. pp. 123-142). Oxford. UK: Elsevier.

Patton, M. Q. (1990). Qualitative evaluation and research methods (2nd ed.). Newbury Park, CA: Sage Publication.

Prewitt, J. \& Weil, R., \& McClure, A., (2011). Developing leadership in global and multi-cultural organizations. International Journal of Business and Social Science, 2(13), 13-20.

Rhinesmith, S. H. (1996a.), A manager's guide to globalization: Six skills for success in a changing world (2nd Ed.), New York, NY: The Mc Graw-Hill.

Rhinesmith, S. H. (1996b.). Open the door to global mind-set. Training \& Developing May 1995: 35-43

Spreitzer, G. M „ McCall, M. W. Jr., \& Mahoney, J. (1997). The early identification of international executive potential. Journal of Applied Psychology. 82(1): 6-29.

Stogdill, R.M. (1974). Handbook of leadership (1st edition). New York: Free Press.

Suutari, V. (2002). Global leader development: An emerging research agenda. Career Development International, 7(4): 218-233.

Swanson, R. A. (Ed.). (2001). Origins of contemporary human resource development. Advances in Developing Human Resources, 3(2). Thousand Oaks, CA: Sage.

Terrell, S. and Rosenbusch, K. (2013). Global leadership development: What global organization can do to reduce leadership risk, increase speed to competence, and build global leadership muscle. People \& Strategy, 36(1), 41-46.

Thorn, M (2012). Leadership in international organizations: global leadership competencies. The Psychologist-Manager Journal, 15:158163

Tubbs, S.L., \& Schulz, E. (2006). Exploring a taxonomy of global leadership competencies and meta-competencies [electronic version]. Journal of American Academy of Business, Cambridge, 8, 29

Yukl, G. A. (1994). Leadership in organizations (3rd Ed). Englewood Cliffs, NJ: Prentice-Hall. 